\title{
Bearing fault detection using motor current signal analysis based on wavelet packet decomposition and Hilbert envelope
}

\author{
Yacine Imaouchen ${ }^{1,}$, Rezak Alkama ${ }^{1}$ and Marc Thomas ${ }^{2}$ \\ ${ }^{1}$ Electrical Engineering Laboratory, Electrical Department, University of Bejaia, Algeria \\ ${ }^{2}$ Department of Mechanical Engineering, École de Technologie Supérieure, Montréal, Qc, H3C 1K3, Canada
}

\begin{abstract}
To detect rolling element bearing defects, many researches have been focused on Motor Current Signal Analysis (MCSA) using spectral analysis and wavelet transform. This paper presents a new approach for rolling element bearings diagnosis without slip estimation, based on the wavelet packet decomposition (WPD) and the Hilbert transform. Specifically, the Hilbert transform first extracts the envelope of the motor current signal, which contains bearings fault-related frequency information. Subsequently, the envelope signal is adaptively decomposed into a number of frequency bands by the WPD algorithm. Two criteria based on the energy and correlation analyses have been investigated to automate the frequency band selection. Experimental studies have confirmed that the proposed approach is effective in diagnosing rolling element bearing faults for improved induction motor condition monitoring and damage assessment.
\end{abstract}

\section{Introduction}

In order to ensure the availability of industrial systems and the safety of goods and persons, the monitoring and diagnosis of bearing defects are of prime importance. Thus, defect detection in rolling elements bearings has been the subject of extensive researches. Different experimental methods have been proposed for detection and diagnosis of bearings which may be broadly classified as vibration and acoustic measurements [1], temperature measurements, defect signatures in the stator current of motors, wear debris and lubricant analysis. More recent studies on induction motors concentrate on monitoring electrical signals such as stator current, because the vibration produced by defects is also modulated on the stator current. Many methods are proposed for diagnosing bearing faults using stator current. The Fast Fourier Transform (FFT) is a standard method for observing signals in the frequency domain and has been widely studied. In spite of its earlier popularity, Fourier transform presents certain serious theoretical drawbacks in signal processing because the time-frequency information is lost. Wavelet analysis overcomes the drawbacks of Fourier methods and permits adaptive time-frequency representation [2]. For example, Gong et al. [3] have shown that the wavelet analysis is more sensitive and reliable than the Fourier analysis for recognizing the tool wear states in turning. Pan et al. [4] also checked the robustness of the wavelet transform method compared to the spectra method of FFT. The signal processing approaches that deal with non-stationary signals are more appropriate for process monitoring [5]. In this research, an outer race bearing defect is detected using the stator current analysis. The Hilbert transform first extracts the

\footnotetext{
${ }^{a}$ Corresponding author: imaoucheny@yahoo.fr
}

envelope of the motor current signal, which contains bearings fault-related frequency information [6,7]. Then, the envelope signal is adaptively decomposed into a number of frequency bands by Meyer wavelet in the wavelet packet structure, with energy comparison as the fault index [8]. Finally, spectra of the selected bands are compared between those obtained by the normal WPD and those obtained by the proposed method.

\section{Theoretical study}

\subsection{Discrete wavelet transform (DWT) and wavelet packet decomposition (WPD)}

Continuous wavelet transforms are recognized as effective tools for both stationary and non-stationary signals. However, they involve much redundant information and are computationally very slow. Discrete wavelet transforms were developed by Mallat with fast algorithm based on the conjugate quadratic filters (CQF) [9]. Wavelet and scaling functions at different scales are generated from a single scaling function $\Phi(t)$ with two-scale difference equations [10]:

$$
\begin{aligned}
& \Phi(\mathrm{t})=\sqrt{2} \sum_{k} h(k) \Phi(2 t-k) \\
& \psi(\mathrm{t})=\sqrt{2} \sum_{k} g(k) \Phi(2 t-k)
\end{aligned}
$$

where $g(k)=(-1)^{k} h(1-k)$, and the $h(k)$ and $g(k)$ are viewed as filter coefficients of low-pass and high-pass filters, and 1 is the filter length. $\Phi(t)$ and $\psi(t)$ are scaling and wavelet functions at scale $j=1$, respectively.

In an orthogonal wavelet expansion, a set of recursive relationships governs scaling and wavelet coefficients at 


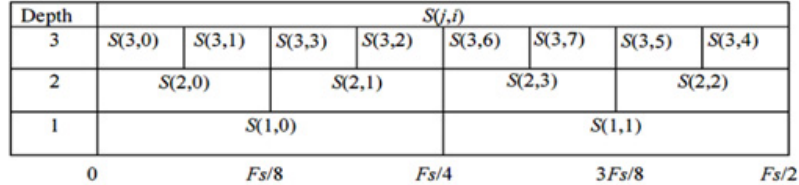

Figure 1. The diagram three-level wavelet packet decomposition tree.

different scales and translations as follows:

$$
\begin{aligned}
c_{j, k} & =\sum_{l} h_{l-2 k} c_{j+1, l} \\
d_{j, k} & =\sum_{l} g_{l-2 k} c_{j+1, l}
\end{aligned}
$$

where $c_{j, k}, d_{j, k}$ are scaling and wavelet coefficients derived from the projection of the signal onto the space of scaling $\Phi_{j, k}(t)$ and wavelet functions $\psi_{j, k}(t)$, respectively.

The DWT leads to a loss of useful information at high frequency because successive details are no longer analyzed. We need to double the sampling rate for higher frequency analysis, which however involves more data and computation. Wavelet packet decomposition [11] is a generalization of wavelet decomposition at higher frequencies. In the wavelet packet decomposition, each approximate and detail coefficients are recursively decomposed. Normally, the frequency localization of wavelet packets is very difficult to analyse. The Fourier transform of Eqs. (5) and (6) proves that the Fourier transform of wavelet packet basis is related to its mother by:

$$
\begin{aligned}
W_{2 n}^{j} & =\sqrt{2} \sum_{k} h(k) W_{n}(2 t-k) \\
W_{2 n+1}^{j} & =\sqrt{2} \sum_{k} g(k) W_{n}(2 t-k)
\end{aligned}
$$

where the functions $W_{0}$ and $W_{1}$ are set to the scaling function $f(x)$ and the mother wavelet function $\psi(x)$, respectively.

The implementation of the wavelet packets leads to a tree-structured decomposition, thereby implying that both the outputs of the low-pass and high-pass filters are recursively decomposed. The energy of $W_{j}^{p}$ is mostly concentrated over a frequency band, and two filters $h\left(2^{j} w\right)$ and $g\left(2^{j} w\right)$ select lower or higher frequency components within this band respectively. Coefficient energy at each node is computed by:

$$
E=\left(\frac{\sum_{k=1}^{M}\left(d_{j}^{p}(k)\right)^{2}}{M}\right)^{1 / 2}
$$

where $M$ is the number of samples at the node, $d$ is the WPT coefficients.

The resulting three-scale analysis tree (three-stage tree) is illustrated in Fig. 1. $F_{s}$ is the frequency sampling.

\subsection{Proposed diagnosis method}

Motor current induced by the bearing defect is modulated by the supply voltage frequency and the envelope of

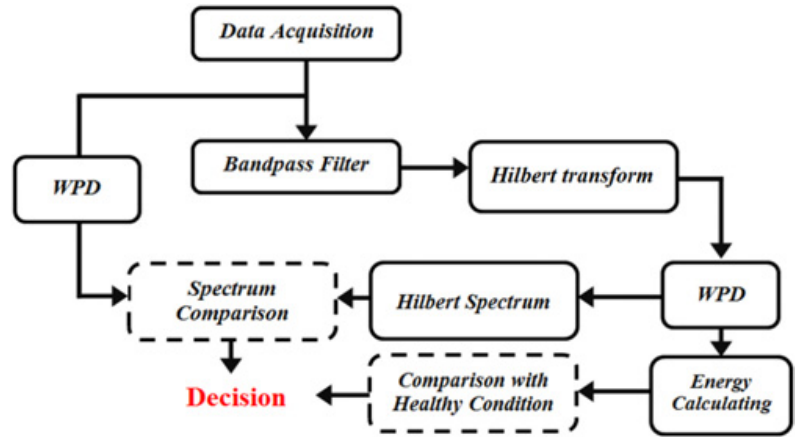

Figure 2. The diagram of the WPD based diagnosis method.

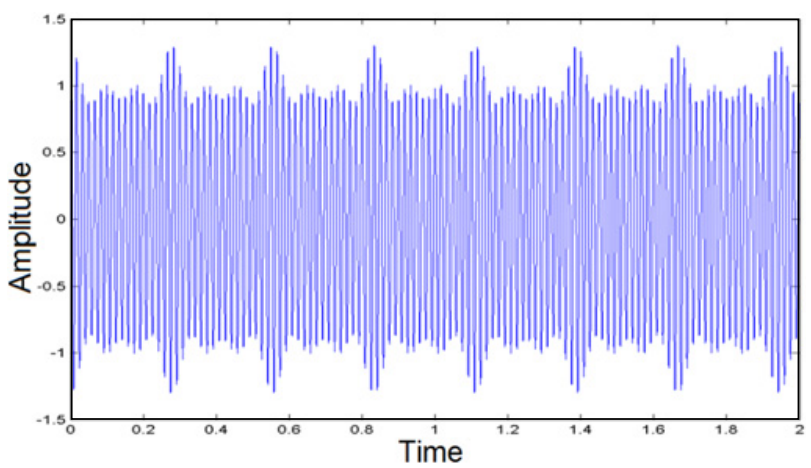

Figure 3. The simulation signal.

the current signal contains the defect and fault-related frequencies. Thus the defect identification process can be achieved through a multi-step signal decomposition and feature extraction process, as illustrated in Fig. 2. The envelope of the signal is first extracted using a digital bandpass filter and Hilbert transform. Next, the envelope signal is decomposed through the WPD. Two criteria based on the energy and correlation analyses have been investigated to select the bands which contain bearings fault-related frequency information. The bands that are most correlated with the defect features are chosen for the Hilbert spectrum analysis.

To evaluate the effectiveness of the Hilbert Envelope, a motor current signal is constructed for numerical simulations. The line current signal is modulated by both the supply frequency and fault-related frequencies.

$$
\begin{aligned}
I(t)= & \cos (2 \pi f t)[1+0.1 \cos (2 \pi(2 c f) t) \\
& +0.1 \cos (2 \pi(4 c f) t+0.1 \cos (2 \pi(6 c f) t)] .
\end{aligned}
$$

Here, c, slip of the motor, has the assumed value of 0.03 , and supply frequency $f$ is set as $60 \mathrm{~Hz}$ (America).

The simulated signal (Fig. 3) shows repetitive impacts [12] and its spectrum are displayed in Fig. 4, from which it is seen that a zoom on spectral analysis of the signal shows the main frequency $(60 \mathrm{~Hz})$ modulated by $3.6 \mathrm{~Hz}$ (2cf). These modulation frequencies are $49.2 \mathrm{~Hz}, 52.8 \mathrm{~Hz}$, $56.4 \mathrm{~Hz}, 63.6 \mathrm{~Hz}, 67.2 \mathrm{~Hz}$, and $70.8 \mathrm{~Hz}$. It is then more difficult in revealing fault related frequencies.

The Hilbert envelop of the signal is shown in Fig. 5a. On the Fourier spectrum of the Hilbert envelope (Fig. 5b), we can see the frequency components at $3.6 \mathrm{~Hz}$, $7.2 \mathrm{~Hz}$, and $10.8 \mathrm{~Hz}$ are dominant. These are related 


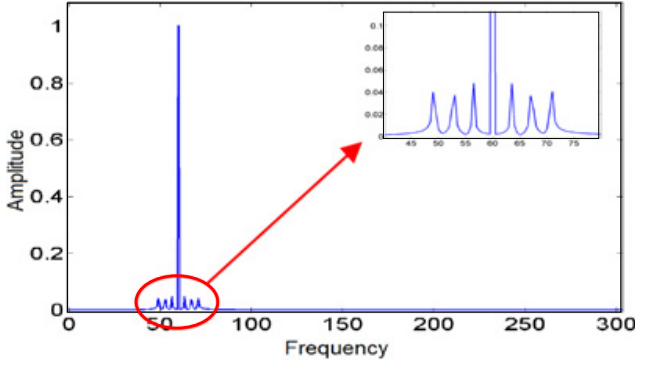

Figure 4. The simulated signal spectrum.
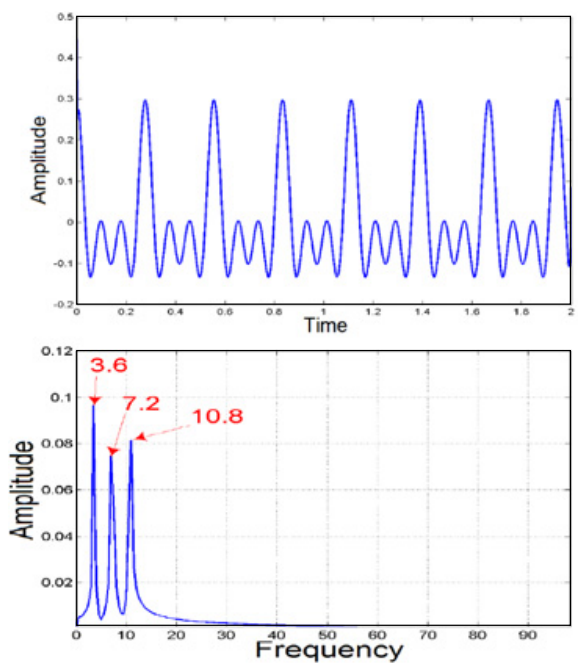

(a)

(b)

Figure 5. Hilbert envelope of the simulation signal (a) and its spectrum (b).

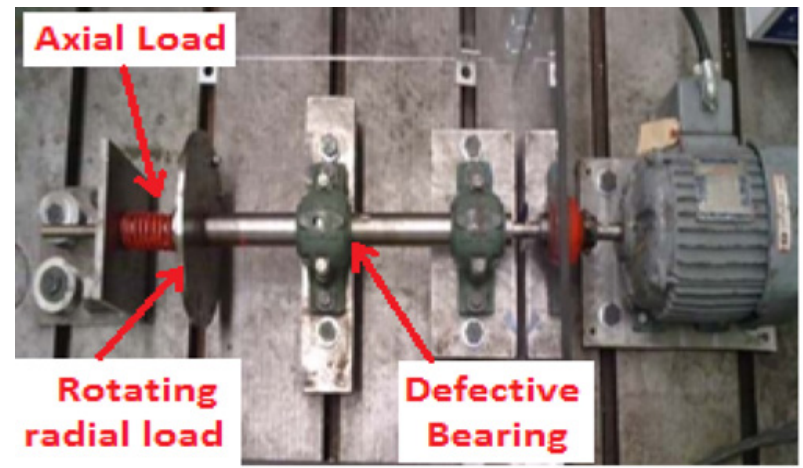

Figure 6. Test bench.

to the $2 c f, 4 c f$, and $6 c f$ fault frequencies known in the synthetic signal.

\section{Experimental results}

In this study, the rolling bearings used are bearings double row ball (SKF, 1210 EKTN9). The data acquisition of experimental signals was made from a bench having a shaft supported by two bearings, a healthy one and an artificially damaged one (Fig. 6). The motor is alimented by $380 \mathrm{~V}$, $30 \mathrm{~Hz}$ and different shaft speeds were applied but we only present the $900 \mathrm{rpm}$ case $\left(f_{r}=15 \mathrm{~Hz}\right)$ in this study. We investigated a fault on the outer race of the bearing. The stored stator current was used as a baseline while bearing
Table 1. Characteristic vibration frequency and modulation effect on the stator current.

\begin{tabular}{llll}
\hline $\mathrm{f}_{a}$ & $F_{r}$ & $\begin{array}{l}\text { Modulation effect on stator } \\
\text { current }\end{array}$ & $\begin{array}{l}\text { Related } \\
\text { nodes }\end{array}$ \\
\hline \multirow{3}{*}{$30 \mathrm{~Hz}$} & $15 \mathrm{~Hz}$ & $\left|\mathrm{f}_{a}-\mathrm{BPFO}\right|=86.6 \mathrm{~Hz}$ & $(11-04)$ \\
& & $\left|\mathrm{f}_{a}-\mathrm{BPFO}\right|=146.6 \mathrm{~Hz}$ & $(11-10)$ \\
& & $\left|\mathrm{f}_{a}-\mathrm{BPFO}\right|=203.26 \mathrm{~Hz}$ & $(11-25)$ \\
& & $\left|\mathrm{f}_{a}-\mathrm{BPFO}\right|=263.26 \mathrm{~Hz}$ & $(11-29)$ \\
\hline
\end{tabular}

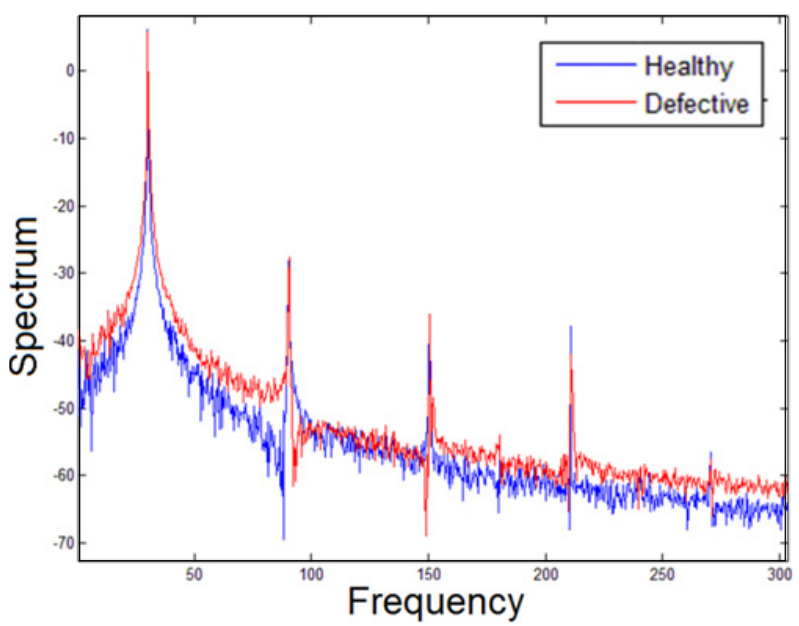

Figure 7. Stator current spectrum: blue line of healthy bearing; red line the bearing with a spall in the outer race.

was in a healthy condition. In a second experiment, a $1.06 \mathrm{~mm}$ spall was drilled on the outer race as a defect. The localized defect was created on the outer race by using an electric discharge machine to keep their size and depth under control. Three signals were conducted for all tests and averaged to evaluate the ability of the proposed method. The characteristic vibration frequency of the outer race defect was computed to $\mathrm{BPFO}=116.6 \mathrm{~Hz}$. Since mechanical vibrations produce anomalies in the air gap flux density, they result in the modulation of stator current. These frequencies can be calculated by [13]:

$$
f_{b n g}=\left|f_{a} \pm m \cdot f_{v}\right|
$$

where $\mathrm{m}=1,2,3, \ldots$ and $f_{a}$ is the electrical power supply frequency and $f_{v}$ is one of the characteristic vibration frequencies which represents the BPFO (in our case) and the modulated frequency on stator current is derived by (9), as shown in Table 1.

In all these tests, the machine was connected to a line directly, and the stator current was sampled at $F_{s}=48 \mathrm{kHz}$ before and after defects were made. Figure 7 shows the average periodogram of signals with a sample number of 240 000. As seen in Fig. 7, it is very difficult to detect the defect by using conventional spectral analysis (small variation of amplitude).

The stator current envelope was then analysed with the wavelet packets transform method. In the first step, the stator current is decomposed into 11 levels for a good resolution. Therefore, we have $2^{11}$ nodes at the ending level for which the frequency resolution is $11.72 \mathrm{~Hz}$. In our case, the DMeyer wavelet was applied for better resolution [14]. Afterwards the energy is computed at all nodes. 
Table 2. Energy comparison around $86.6 \mathrm{~Hz}$ (outer race defect frequency).

\begin{tabular}{llll}
\hline \multirow{2}{*}{ Condition } & \multicolumn{3}{l}{ Frequency range } \\
\cline { 2 - 4 } & $\begin{array}{l}\text { Node }(11-5) \\
(70.31-\end{array}$ & $\begin{array}{l}\text { Node }(11-4) \\
(82.03-\end{array}$ & $\begin{array}{l}\text { Node }(11-12) \\
(93.75-\end{array}$ \\
& $82.03 \mathrm{~Hz})$ & $93.75 \mathrm{~Hz})$ & $105.46 \mathrm{~Hz})$ \\
\hline Healthy & 0.47 & 0.22 & 2.17 \\
Outer race & 0.9 & 5.16 & 2.38 \\
defect & & & \\
\hline
\end{tabular}

Table 3. Energy comparison around $146.6 \mathrm{~Hz}$ (outer race defect frequency).

\begin{tabular}{llll}
\hline \multirow{2}{*}{ Condition } & \multicolumn{3}{l}{ Frequency range } \\
\cline { 2 - 4 } & $\begin{array}{l}\text { Node }(11-14) \\
(128.9-140.6 \mathrm{~Hz})\end{array}$ & $\begin{array}{l}\text { Node }(11-10.6- \\
152.3 \mathrm{~Hz})\end{array}$ & $\begin{array}{l}\text { Node }(11-11) \\
(152.3-164.1 \mathrm{~Hz})\end{array}$ \\
\hline Healthy & 0.023 & 0.016 & 0.17 \\
$\begin{array}{l}\text { Outer race } \\
\text { defect }\end{array}$ & 0.23 & 0.84 & 0.28 \\
\hline
\end{tabular}

Table 4. Energy comparison around $203.26 \mathrm{~Hz}$ (outer race defect frequency).

\begin{tabular}{llll}
\hline \multirow{2}{*}{ Condition } & \multicolumn{3}{c}{ Frequency range } \\
\cline { 2 - 4 } & Node $(11-24)$ & Node $(11-25)$ & Node $(11-27)$ \\
& $(128.9-140.6 \mathrm{~Hz})(199.2-$ & $(210.9-$ \\
& & $210.9 \mathrm{~Hz})$ & $222.6 \mathrm{~Hz})$ \\
\hline Healthy & 0.013 & 0.014 & 0.014 \\
$\begin{array}{l}\text { Outer race } \\
\text { defect }\end{array}$ & 0.17 & 0.27 & 0.29 \\
\hline
\end{tabular}

Table 5. Energy comparison around $263.26 \mathrm{~Hz}$ (outer race defect frequency).

\begin{tabular}{llll}
\hline \multirow{2}{*}{ Condition } & \multicolumn{3}{c}{ Frequency range } \\
\cline { 2 - 4 } & $\begin{array}{l}\text { Node }(11-24) \\
(246.1-\end{array}$ & $\begin{array}{l}\text { Node }(11-29) \\
(257.8-269.5 \mathrm{~Hz})(269.5-\end{array}$ \\
& $257.8 \mathrm{~Hz})$ & & $281.2 \mathrm{~Hz})$ \\
\hline $\begin{array}{l}\text { Healthy } \\
\begin{array}{l}\text { Outer race } \\
\text { defect }\end{array}\end{array}$ & 0.007 & 0.044 & 0.004 \\
\hline
\end{tabular}

\subsection{Energy comparison}

In Table 2, the energy is compared around the outer race defect frequency $(116.6 \mathrm{~Hz}-30 \mathrm{~Hz}=86.6 \mathrm{~Hz})$ for the two cases, healthy and defective bearing. The largest energy is related to the node $(11-4)$. As can be seen from this table, energy is increased for other cases. This is caused by the modulation effect of sidebands which is a feature characteristic of a defect in rotating machinery.

Examining the Table 3, the energy is compared around $146.6 \mathrm{~Hz}(116.6 \mathrm{~Hz}+30 \mathrm{~Hz})$. Since the bearing has an incipient outer race defect, the energy is slightly increased. As expected, the increase of energy is better viewed in this concerning node $(11-10)$.

Energy variations around $203.26 \mathrm{~Hz}$ and 263.26 related to the outer race defect are shown in Tables 4 and 5 respectively.

In comparison with Table 2 , it is observed that the energy increase happened around these frequencies, in
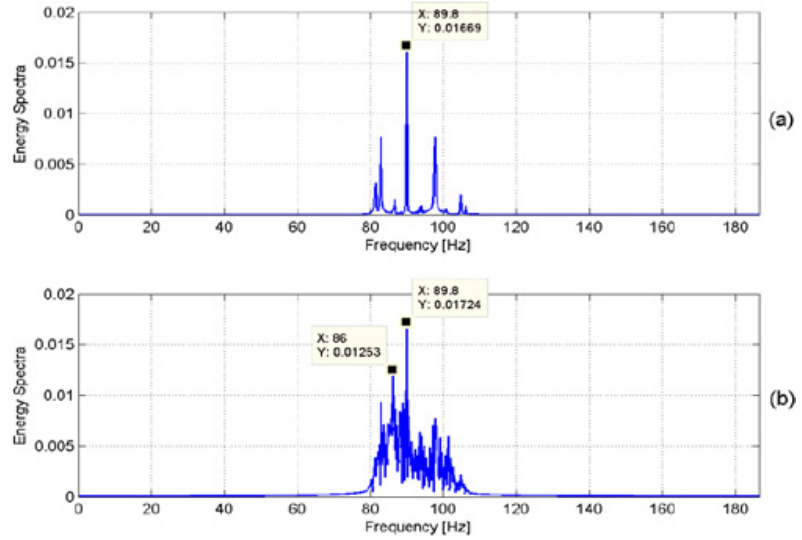

Figure 8. Energy spectra of the band around $86.6 \mathrm{~Hz}$ : (a) classical method; (b) proposed method.
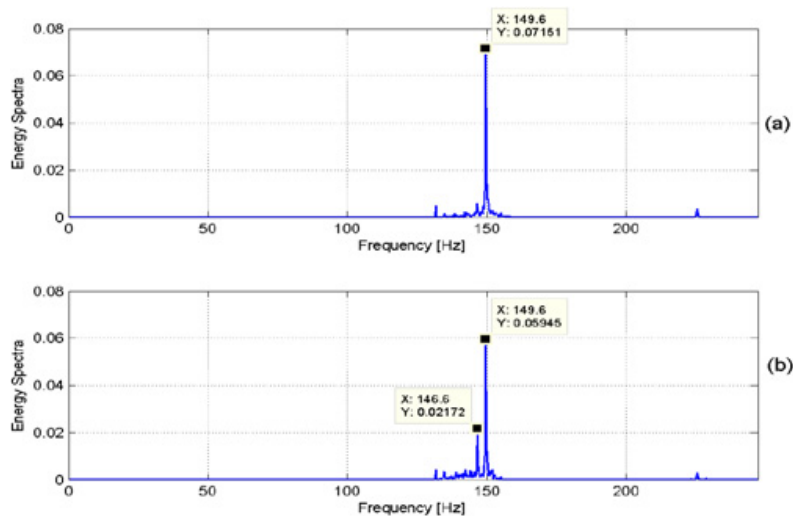

Figure 9. Energy spectra of the band around $146.6 \mathrm{~Hz}$ : (a) classical method; (b) proposed method.

the addition of the increase around $86.6 \mathrm{~Hz}$. This fact is interpreted as the modulation of stator current by vibration component as follows: vibration signals of the motor housing were evaluated using combination of envelope and WPT methods.

It was noticed that in the vibration spectrum, instead of a component in $B P F O=116.6 \mathrm{~Hz}$, harmonics of $2 \times B P F O, 3^{*} B P F O \ldots$ etc. were observed which were modulated in $86.6,146.6,203.26$ and $263.26 \mathrm{~Hz}$ in the stator current as depicted in Table 1 and calculated by the Eq. (9). The harmonics of bearing frequency are characteristic of a defect at the third stage of degradation (residual life lower than 10\%) [15].

\subsection{Spectrum comparison}

The application of Fourier spectra to the characteristic narrow frequency bands selected by the WPD can't allow for clearly identifying the frequency related to the fault, while the proposed method reveals all the characteristic frequency modulated in the current signal envelope, when WPD is applied to the signal envelope. As Fig. 8 shows, one can see clearly the component $86.6 \mathrm{~Hz}$ in the spectrum of the proposed method ( $8 b)$ contrary to the (8a) where it's almost completely hidden.

The second component $(146.6 \mathrm{~Hz})$ that characterize also the fault is betrayed by the spectrum shown in 
Fig. 9b. However, a small pic of amplitude at this frequency is shown in Fig. 9a.

We notify that the same statement is obtained towards the two other components at their characteristic narrow bands. This proves the efficiency of the proposed method to reveal the fault frequencies.

\section{Conclusions}

In this paper, Wavelet Packet Analysis is used as a powerful diagnostic method for the detection of incipient bearing failures via stator current analysis. Hilbert transform first extracts the envelope of the motor current signal, which contains bearings fault-related frequency information. A current signal processing algorithm applied to electric current signals is proposed as a suitable alternative to vibration signal to detect bearing faults. The proposed method presents several advantages over Fourier analysis. Stator current in nature is non-stationary; and therefore, wavelet packet transform can provide better analysis under various conditions. Moreover, the frequency bands in defect detection are more tolerant due to the fact that the actual bearing-defect induced vibration frequency may vary slightly from the predicted values due to slippage that occurs within bearing [12]. Wavelet packet transform can cover this range of frequency band. The proposed method was successfully verified through outer race bearing defect detection.

\section{References}

[1] M. Kedadouche, M. Thomas and A. Tahan. May 2014. Cyclostationarity applied to acoustic emission and development of a new indicator for monitoring bearing defects. Mechanics \& Industry, $16 \mathrm{p}$.

[2] M.S. Safizadeh, A.A. Lakis and M. Thomas, TimeFrequency and Their Application to Machinery Fault Detection, International Journal of Comadem, 5, 2 (2002), pp. 41-57

[3] W. Gong, T. Obikawa, T. Shirakashi, Monitoring of tool wear states in turning based on wavelet analysis, JSME International Journal (Series C) 40, 3(1997), pp. $447-453$
[4] Y. Pan, J. Chen, L. Guo, Robust bearing performance degradation assessment method based on improved wavelet packet - support vector data description, Mechanical Systems and Signal Processing, 23, 3 (2009), 669-681

[5] Sassi S., Badri B. and Thomas M., July 2008. Tracking surface degradation of ball bearings by means of new time domain scalar descriptors, International Journal of Comadem, 11 (3), 36-45

[6] M. Kedadouche, M. Thomas and A. Tahan, 21 april 2014. Monitoring bearing defects by using a method combining EMD, MED and TKEO. Advances in Acoustics and Vibration. Hindawi Publishing Corporation, 2014, $10 \mathrm{p}$.

[7] J. Antoni. The spectral kurtosis: a useful tool for characterising non-stationary signals, MSSP, 20, Issue 2 (2006), pp. 282-307

[8] Meyer Y., Ondelettes et Opérateurs, Hermann, 1990

[9] S.G. Mallat, A Wavelet Tour of Signal Processing, Second Ed., Academic Press, New York (1999)

[10] I. Daubechies, The wavelet transformation, timefrequency localization and signal analysis, IEEE Transactions on Information Theory 36 (1990), 961-1005

[11] L. Eren, and M. J. Devaney, Bearing Damage Detection via Wavelet Packet Decomposition of the Stator Current, Transactions on instrumentation and measurement, 53, 2 (2004), pp. 431-436

[12] Badri B., Thomas M. and Sassi S., A shock filter for bearing slipping detection and multiple damage diagnosis, International Journal of Mechanics, 5, 4 (July 2011) 318-326

[13] M. Blodt, D. Bonacci, J. Regnier, M. Chabert and J. Faucher. On-line Monitoring of Mechanical Faults in Variable-Speed Induction Motor Drives Using the Wigner Distribution. IEEE Transactions on Industrial Electronics, 55, 2 (2008), pp. 522-533

[14] Yan Long, Liu Gang and Guo Jun, Selection of the best wavelet base for speech signal, Proceedings of IMVSP, 20-22 Oct. 2004. IEEE conference ISBN:07803-8687-6

[15] Marc Thomas, Reliability, predictive maintenance and machines vibrations. (In french), Presses de l'Université du Québec (PUQ), Canada, (2011) D3357, ISBN 978-2-7605-3357-8 